\title{
Pharmaceutical Compounding: a History, Regulatory Overview, and Systematic Review of Compounding Errors
}

\author{
C. James Watson ${ }^{1,2}$ (D) $\cdot$ James D. Whitledge ${ }^{2} \cdot$ Alicia M. Siani $^{3} \cdot$ Michele M. Burns $^{1,4}$
}

Received: 30 June 2020 / Revised: 13 September 2020 / Accepted: 17 September 2020 / Published online: 2 November 2020

(C) American College of Medical Toxicology 2020

\begin{abstract}
Introduction Medications are compounded when a formulation of a medication is needed but not commercially available. Regulatory oversight of compounding is piecemeal and compounding errors have resulted in patient harm. We review compounding in the United States (US), including a history of compounding, a critique of current regulatory oversight, and a systematic review of compounding errors recorded in the literature.

Methods We gathered reports of compounding errors occurring in the US from 1990 to 2020 from PubMed, Embase, several relevant conference abstracts, and the US Food and Drug Administration "Drug Alerts and Statements" repository. We categorized reports into errors of "contamination," suprapotency," and "subpotency." Errors were also subdivided by whether they resulted in morbidity and mortality. We reported demographic, medication, and outcome data where available.

Results We screened 2155 reports and identified 63 errors. Twenty-one of 63 were errors of concentration, harming 36 patients. Twenty-seven of 63 were contamination errors, harming 1119 patients. Fifteen errors did not result in any identified harm.

Discussion Compounding errors are attributed to contamination or concentration. Concentration errors predominantly result from compounding a prescription for a single patient, and disproportionately affect children. Contamination errors largely occur during bulk distribution of compounded medications for parenteral use, and affect more patients. The burden falls on the government, pharmacy industry, and medical providers to reduce the risk of patient harm caused by compounding errors.

Conclusion In the US, drug compounding is important in ensuring access to vital medications, but has the potential to cause patient harm without adequate safeguards.
\end{abstract}

Keywords Compounding $\cdot$ Pharmacy $\cdot$ Error $\cdot$ Contamination $\cdot$ Toxicology $\cdot$ Regulation

Prior Presentations: None

Supervising Editor: Michael Hodgman, MD

C. James Watson

cjwatson@bidmc.harvard.edu

1 Harvard Medical Toxicology Program, Boston Children's Hospital, 333 Longwood Avenue, Mailstop 3025, Boston, MA 02215, USA

2 Department of Emergency Medicine, Beth Israel Deaconess Medical Center, Boston, MA, USA

3 School of Law, Boston University, MA Boston, USA

4 Division of Emergency Medicine, Boston Children's Hospital, Boston, MA, USA

\section{Introduction}

In the modern-day United States (US), medications are by-inlarge manufactured in commercial facilities, and this production is regulated and overseen by the US Food and Drug Administration (FDA). Historically, however, medications were mixed —or compounded - by independent pharmacists for use by individual patients. While traditional compounding is becoming less prevalent, it still occurs in instances where a particular patient may require a formulation of a medication that is not otherwise available. Furthermore, a new form of large-scale compounding has become commonplace, whereby pharmacies produce bulk volumes of medications which are not available commercially, and broadly distribute them to healthcare practices and individual patients.

Compounding does not traditionally fall under the purview of FDA oversight, instead being regulated by individual 
states' boards of pharmacy. This approach has resulted in a patchwork and oftentimes underfunded regulatory framework, which has subsequently harmed patients [1-4]. Morbidity and mortality frequently result either from a compounded medication that is contaminated with bacteria, fungi, or another medication during production, or from an error whereby the concentration of the drug dispensed is not as intended, which can lead to inadvertent over- or underdosing. Patient harm caused by compounded medications has been the focus of media, medical, and legislative attention in recent years, especially following a multistate, multi-fatality outbreak of fungal meningitis caused by contaminated steroid injections compounded at a pharmacy in Framingham, MA [2, $3,5,6]$.

This article seeks to provide a comprehensive review of the state of outpatient compounding in the US. Compounding performed by hospital pharmacies for inpatient use is beyond the scope of this paper. Much has been written on compounding pharmaceuticals; this paper is an effort to succinctly address the history, purpose, and regulatory framework in a unified location, as well as to perform a systematic review of all US compounding errors over the past 30 years. To our knowledge, no systematic review of both contamination and non-contamination errors has to this point been undertaken. We will first explore the definition and modern role of compounding. Then, we will briefly discuss the modern US history of compounding, with a particular focus on factors influencing the current state of compounding. Next, we will examine compounding through a legislative and regulatory lens, to better decipher how governmental oversight - or a lack thereof-may contribute to errors in compounding resulting in patient harm. Understanding the interventions being made on a federal level can help improve the safety of compounding. Finally, we have performed a systematic review of documented compounding errors and categorized those errors by type and patient outcome. Whereby, we elucidate just how and with what frequency patients are harmed by compounding errors, with the ultimate aim of identifying potential strategies for reducing these adverse events.

\section{Compounding: What It Is and Why It Is Essential}

Compounding is defined by the FDA as the combination, mixing, or alteration of drug ingredients to create medications tailored to individual patient needs [7]. The United States Pharmacopeia (USP), which sets quality standards for drugs, describes compounding as "the preparation, mixing, assembling, altering, packaging, and labeling of a drug ... in accordance with a licensed practitioner's prescription ..." [8] Put simply, it is the creation of a medication that is not commercially available.
In the US, compounding is performed in both the inpatient hospital setting and in outpatient pharmacies, with a trend in recent decades towards larger scale outpatient production [9]. As will be discussed later in this paper, compounding may now occur in newly defined "outsourcing facilities," which are designed to compound in bulk; some examples of these facilities include QuVa Pharma and Leiters [10]. There are many indications for compounding. Some patients may not tolerate pills and require a compounded liquid drug formulation; examples include young children taking antibiotics, feeding tube-dependent patients, or patients with dysphagia from neurologic compromise such as a stroke $[11,12]$. Patients may be allergic to binding agents, dyes, diluents, or other inactive ingredients in commercially available formulations. Dietary restrictions, such as a ketogenic diet in pediatric epilepsy patients, may necessitate compounding of sugar-free medications [13]. Refractory neuropathic pain may benefit from compounded analgesic topical creams containing multiple medications not commercially available in combination; examples include ketamine, baclofen, gabapentin, amitriptyline, bupivacaine, and clonidine [14]. Painful oral lesions can be treated with "magic mouthwash" and dyspepsia can be treated with a "gastrointestinal (GI) cocktail"; these are terms that actually encompass a range of compounded preparations [15]. Total parenteral nutrition (TPN) is needed for patients unable to take in sufficient oral nutrition, and numerous chemotherapy regimens must be compounded for cancer treatment $[16,17]$. Healthcare providers may need compounded medications to perform specialized procedures such as intraarticular or intravitreal injections. In some instances, commercial preparations may be available but expensive, and a compounded equivalent is more affordable [18]. Drug shortages, a longstanding healthcare problem exacerbated by crises such as the COVID-19 pandemic and the devastation of Puerto Rico by Hurricane Maria, may be addressed by compounding as well $[19,20]$. The FDA has responded to significant shortages during the COVID-19 pandemic by temporarily relaxing restrictions on compounding of commercially available drugs [21, 22].

When a compounded medication is prescribed or administered, patient safety depends on adherence to Current Good Manufacturing Practices (CGMP), which are outlined in Chapter 795 of the USP for non-sterile preparations and Chapter 797 for sterile preparations. Appropriateness of the prescription indication, safety, and dosing should be assessed by the pharmacist. Ingredient quantities must be meticulously calculated, and the source quality of those ingredients assured. Compounding facilities and equipment must be clean and monitored continuously. Staff must routinely practice and be assessed for competency in proper hygienic measures. Sterile preparations, by definition, require a higher level of care to prevent contamination than do non-sterile preparations, including differences in staff training and personal protective 
equipment (PPE), environment and air quality monitoring, and disinfection. Compounded sterile preparations are further subdivided into low-, medium-, and high-risk depending upon the quantity of ingredients, number of manipulations required during compounding, and whether nonsterile ingredients requiring subsequent sterilization are incorporated. Multiple medications must not be simultaneously compounded in the same workspace. The compounding process must be reproducible such that medication quality is consistent throughout many production cycles. Finally, prescriptions must be correctly labeled and patients instructed in appropriate use [8, 23-25]. Failure to adhere to these standards has the potential to result in patient harm through multiple mechanisms including medication suprapotency, subpotency, contamination, and consumer misuse.

\section{Historical Context}

Throughout pre-industrial history, pharmacists played the critical role of admixing various materials to produce a finished therapeutic substance. This role was, in essence, one of compounding $[26,27]$. However, the industrial revolution and the resultant mass production of pharmaceuticalscoupled with the increasing presence of synthetic proprietary medications - led to a change in pharmacists' primary role. Instead of compounding, community pharmacists in the early 1900 s turned their focus to the dispensing of previously manufactured medications as well as to general retail, including operating the soda fountains which came into vogue with the prohibition of alcoholic beverages. In fact, by the 1930s, fewer than $1 \%$ of pharmacies in the US made a majority of their income from pharmaceutical sales [27].

The decline in community pharmacy compounding was precipitous through the mid-1900s. In the 1930s, $75 \%$ of prescriptions required some sort of in-pharmacy compounding. That number fell to $25 \%$ by the 1950 s, less than $5 \%$ by 1960 , and to $1 \%$ by 1970 [28]. Interestingly, there was a concurrent increase in the need for hospital pharmacy compounding during the same period; largely due to the advent of chemotherapy, TPN, and cardiac surgery which necessitated the administration of complex cardioplegic regimens. By the 1980s, these advanced therapeutics began to spill into the outpatient setting, generating a novel home infusion industry for treatments such as TPN, antibiotics, and chemotherapeutics [29]. As a result, the 1990s and 2000s yielded further diversification within the compounding industry as pharmacies began to compound in bulk. This development was brought about by expanding home infusion programs, the more frequent outsourcing of hospital compounding to the outpatient setting, and the rise of hormone replacement therapy. Large volume compounding blurs the line between traditional compounding which has state-based regulatory oversight, and the mass manufacture of pharmaceuticals which falls under wellestablished federal FDA regulations [29-31].

The inspiration for this article is a well-documented history of medication errors attributable to pharmaceutical compounding, for which a lack of regulatory oversight persists as a common thread [3, 29, 32, 33]. The most lethal and infamous of these cases occurred in 2012, when an outbreak of fungal meningitis occurred amongst patients who had received epidural spinal injections. The outbreak affected 753 patients across 20 states, killing 64 [5, 6, 34, 35]. Ultimately, the outbreak was linked to a compounding pharmacy, the New England Compounding Center (NECC, located in Framingham, MA). Amongst other pharmaceuticals, NECC produced injectable sterile methylprednisolone acetate for epidural injections, which it then distributed nationally. Following the outbreak (hereafter "Framingham"), the FDA determined that the pharmacy had disregarded basic sanitary standards and had not taken corrective measures despite internal knowledge of potential contamination [2, 5, 6, 34-36]. As with many compounding pharmacies, NECC operated in a historically murky regulatory space, producing medications in bulk as would a commercial pharmaceutical manufacturer, while only being subjected to reduced state oversight given to compounding pharmacies. In fact, in the years preceding the outbreak, the FDA had thrice investigated NECC and found sterility violations, but they were unable to enforce any interventions or penalties due to the FDA's contested regulatory jurisdiction [4]. Both preceding and following Framingham, efforts have been made at the federal level to improve oversight of compounding; these are reviewed in depth later in this article. Currently, there is incomplete tracking of compounded pharmaceuticals in the US, though they are estimated to comprise $1-3 \%$ of all prescriptions [30, 31, 37, 38]. Ultimately, compounding is highly prevalent, and so clinicians must be familiar with the risks associated with compounded medications as they care for patients who may be suffering from a related adverse event.

\section{Regulatory and Legislative Framework}

Prior to Framingham, modern compounding pharmacies evolved within a regulatory framework that lacked distinct federal or state oversight roles. In 1938, the Federal Food, Drug, and Cosmetic Act (FDCA) authorized FDA oversight of pharmaceutical manufacturing [39]. However, because compounders traditionally produced drugs in response to individual prescriptions and on a much smaller scale than conventional drug manufacturers, pharmaceutical compounding developed and remained under the regulatory purview of individual state boards of pharmacy $[32,40]$. Towards the end of the twentieth century, pharmacies began bulk compounding in response to (1) the home infusion industry 
and (2) hospitals' financial interest in outsourcing compounding from their inpatient pharmacies to the outpatient setting [29]. Concerned that bulk compounders were self-classifying as pharmacies to avoid the rigorous federal oversight required of drug manufacturers under the FDCA, Congress passed the 1997 Food and Drug Administration Modernization Act (FDAMA) [40]. FDAMA addressed the changing nature of compounding pharmacies by creating a "safe harbor" exempting pharmacies from the more stringent FDCA regulations so long as compounders refrained from advertising their product and abided by requirements designed to increase drug safety [40, 41].

Despite Congress's attempt to strengthen oversight of compounding pharmacies, litigation challenging FDAMA tempered the FDA's authority to regulate compounders. In 2002, a narrowly divided US Supreme Court ruled in Thompson v. Western States Medical Center that the FDAMA advertising prohibition was unconstitutional on First Amendment free speech grounds [42]. The ensuing regulatory confusion is well described in the literature, and the details are beyond the scope of this review $[3,28,29,31,32$, 40]. For reference, a summary of the relevant legislation and litigation is provided in Fig. 1. Decades of regulatory uncertainty culminated in the 2012 Framingham incident, which revived Congressional efforts to address pharmaceutical compounding industry safety concerns.

In response to Framingham, Congress passed and President Barack Obama signed into law the bipartisan-supported Compounding Quality Act (CQA) as part of a broader legislative package (the 2013 Drug Quality and Security Act) [43]. The CQA delineated state and federal oversight authority by defining two distinct categories of compounding pharmacies. The first category is traditional compounding pharmacies, or "503A" pharmacies [44]. 503A pharmacies under the CQA may compound only in response to individual prescriptions. Importantly, 503 A pharmacies may not compound bulk medications either in anticipation of receiving prescriptions or with plans to distribute broadly to healthcare facilities [31, 45]. In exchange for complying with these limitations, 503A pharmacies largely avoid the more burdensome regulations required of drug manufacturers under the FDCA, including adhering to CGMP [31, 37, 46-48]. Accordingly, state boards of pharmacy continue to serve as the primary regulators of 503A pharmacies [45].

The CQA created a second category of compounding pharmacy, called an "outsourcing facility." [49] Unlike 503A pharmacies, outsourcing facilities voluntarily opt-in to this category by paying the FDA a user fee (approximately $\$ 18,298$ in FY2020) [50], and comply with stringent CGMP standards as well as reporting requirements $[38,46]$. Because they submit to more robust FDA oversight, outsourcing facilities are permitted to compound in bulk in advance of receiving a prescription, and may distribute their products across state lines $[31,51]$. Though the FDA enjoys primary regulatory authority over outsourcing facilities, states are not precluded from imposing additional requirements [51]. Should a compounding pharmacy fail to comply with the 503A criteria or voluntarily register as an outsourcing facility, it is subject to the full breadth of regulations required of drug manufacturers under the FDCA [37]. The distinctions between 503A pharmacies and outsourcing facilities are illustrated in Fig. 2.

Following enactment of the CQA, states have taken numerous steps to further develop their respective oversight structures under the new framework. A majority of states have strengthened regulations empowering state boards of pharmacy to hold 503A pharmacies accountable to higher safety practices, such as requiring conformation with recognized sterile compounding guidelines. However, state oversight of 503A pharmacies continues to vary, with fewer than half of all states reporting annual inspections of 503A pharmacies in 2018 [52].

The FDA has similarly adjusted its enforcement priorities $[53,54]$. For example, the CQA permits a 503A pharmacy to distribute no more than $5 \%$ of its total prescriptions out of state

Federal Food Drug \& Cosmetic Act (FDCA) (1938): FDCA authorizes the United States Food and Drug Administration (FDA) to regulate, among other things, drug manufacturing. However, the FDA did not subject compounding pharmacies to the FDCA for decades and instead deferred to the states.

Food Drug Administration Modernization Act (FDAMA) (1997): FDAMA clarified the FDA's regulatory role over compounding pharmacies by formally exempting compounding pharmacies that adhere to certain criteria, including an advertising prohibition, from complying with the more rigorous FDCA requirements.

Thompson v. Western States (2002): The U.S. Supreme Court ruled that the FDAMA advertising prohibition was unconstitutional. Lower courts disagreed on whether the Western States ruling ultimately rendered the entire FDAMA compounding exclusion unconstitutional, leaving the FDA's regulatory role over compounding pharmacies unsettled.

Compounding Quality Act (CQA) (2013): In response to the 2012 Framingham outbreak, Congress passed and President Barack Obama signed into law the CQA as part of the Drug Quality and Security Act. The CQA is further explored in Figure 2.|

Fig. 1 Significant federal legislation and litigation related to compounding pharmacies. 
The Compounding Quality Act (CQA) delineates state and federal oversight authority by establishing two categories of compounding pharmacies: (1) 503A pharmacies and (2) outsourcing facilities.

\section{A Pharmacies:}

- Compounding activities: "Traditional" compounding pharmacies that compound in response to individual prescriptions, rather than compound bulk medications in anticipation of receiving prescription

- Regulations: Largely avoid the more burdensome regulations required of drug manufacturers under the Federal Food Drug \& Cosmetic Act if the 503A pharmacy compounds in response to individual prescriptions and heeds regulations limiting the volume of drugs distributed across state lines

- Primary oversight authority: State governments (state boards of pharmacy)

Outsourcing Facilities:

- Compounding activities: Engage in broader manufacturing than "traditional" 503A pharmacies and are permitted to compound in bulk

- Regulations: Compounding pharmacies may opt into classification as an outsourcing facility by registering with the FDA, paying an annual user fee, and complying with Current Good Manufacturing Practice standards and reporting requirements

- Primary oversight authority: Federal government (United States Food and Drug Administration)

Fig. 2 Key provisions of the 2013 Compounding Quality Act.

unless the pharmacy's home state enters into a Memorandum of Understanding (MOU) with the FDA [55]. The goal of this provision is to avoid another national outbreak by reducing the likelihood that contaminated drugs cross state lines. If a given state enters into a MOU with the FDA, 503A pharmacies in that state may distribute a higher percentage of prescriptions (now up to 50\%) across state lines in exchange for that state's board of pharmacy agreeing to identify, investigate, and report associated adverse events [ 45]. Importantly, the MOU standardizes procedures for state boards of pharmacy to report concerns to the FDA and other states; however, the agreement also grants states significant discretion in how states conduct investigations [54]. In short, states that participate in the MOU, rather than the FDA, will undertake primary responsibility for detecting poor quality or dangerous compounded medications distributed by 503A pharmacies from their state.

The FDA also announced an effort to entice more compounding pharmacies to register as outsourcing facilities by embracing a risk-based approach [45]. Since enactment of the CQA, far fewer pharmacies have registered as outsourcing facilities than the FDA had expected. In fact, the FDA anticipated 50 pharmacies to register per year, but only 78 total were registered as of May 2020 (even fewer than the 91 registered in 2016) $[38,51,56]$. To attract compounding pharmacies - some of which have cited cost of compliance with CGMP as a prohibitively expensive barrier to registering as an outsourcing facility - the FDA plans to reduce CGMP requirements for compounding pharmacies it deems as "lower risk." [45] Though the FDA published draft guidance in 2018 describing how the agency may tailor CGMP requirements for outsourcing facilities, the FDA has yet to issue final guidance on this matter [53,57].

Critics warn that FDA and state efforts to implement the CQA regulatory scheme excludes compounding pharmacies from the decision-making process and may limit patients' access to compounded medications. For example, the Preserving Patient Access to Compounded Medications Act (H.R. 1959) introduced in the US House of Representatives attempts to address complaints expressed by compounders [58]. The proposed legislation seeks to ensure that compounders and other interested parties have an opportunity to comment on (and influence) FDA compounding regulations. Furthermore, the proposed legislation would explicitly allow physicians who engage in in-office sterile compounding, or who otherwise maintain a supply of compounded medications for "office use," to avoid complying (where state law permits) with outsourcing facility regulations [58].

Meanwhile, the sterility practices of some compounding pharmacies continue to raise alarm: between 2013 and 2018, the FDA issued more than 180 warning letters to compounding pharmacies, resulting in approximately 140 recalls. As acknowledged by the agency, the FDA's transition to a risk-based approach may assist the agency in more efficiently targeting its limited resources, but it could also increase the likelihood of compounders engaging in unsafe practices that elude regulators [45]. In sum, the CQA and subsequent state and FDA actions have somewhat clarified oversight roles after Framingham, largely by defining separate 503A pharmacies and outsourcing facilities. Seven years after its enactment, however, uncertainty regarding the relative strength and consistency of said regulatory framework remains.

\section{Methods}

We performed a systematic review of compounding errors, including both errors that resulted in patient harm and those that did not, as reported in the academic literature. We searched the National Center for Biotechnology Information 
(PubMed; U.S. National Library of Medicine: Bethesda, Maryland) and Embase (Elsevier: Amsterdam, The Netherlands) using the following search criteria: “"compounding AND pharmacy' AND 'error,' 'overdos*, 'toxicol*,' 'infect*,' 'death,' 'outbreak,' 'injur*,' OR 'case report."' This search was limited to January 1990 through March 2020. Additionally, we reviewed abstracts for years 1990-2019 for the following conferences using keyword searches for "compound" and "compounding": American College of Medical Toxicology (ACMT) Annual Scientific Meeting, North American Congress of Clinical Toxicology (NACCT), American College of Emergency Physicians (ACEP) Scientific Assembly, Society for Academic Emergency Medicine (SAEM) Annual Meeting, American Academy of Pediatrics (AAP) National Conference \& Exhibition, and the Pediatric Academic Societies (PAS) Meeting. We also reviewed the FDA's online "Drug Alerts and Statements" repository for alerts regarding compounding pharmacies' failures in sterility and potency standards. Authors CJW and JDW screened reports by title and, when necessary for clarification, by abstract. Under manual review, articles were excluded if they were obviously irrelevant, consisted of research comparing samples of compounded and commercial pharmaceuticals, were in a non-English language, regarded medications compounded outside of the US, were redundant with another included report, represented misuse of properly compounded medications, regarded veterinary patients, were compounded by an inpatient hospital pharmacy (including chemotherapeutics and parenteral nutrition), were published prior to 1990 , or if the report lacked sufficient information to provide substantive value. Redundant reports of the same error were included for analysis only once, but efforts were made to reference all identified reporting sources. For included reports, CJW and JDW extracted information including date, type of error, cause of error, number of patients affected, age of patients affected, and clinical course of patients affected. Incomplete data was acknowledged and by-inlarge was not grounds for exclusion from the study.

We categorized errors under the conceptual framework described by Sarah Sellers, PharmD, MPH, former board member for the FDA's Advisory Committee on Pharmacy Compounding, in testimony to the US Senate Committee on Health, Education, Labor, and Pensions, namely, that "suprapotency," "subpotency," and "contamination" are the primary risks associated with pharmaceutical compounding [59]. We further broke down "contamination" into subgroups of "microbiologic contamination" for cases of bacterial, viral, or fungal contamination and "toxic contamination" for noninfectious contaminants. When available, we documented patient age and outcome, route of administration, and medication-in-question, so as to better characterize the types of medications, errors, and patients most associated with adverse events.
We referenced and applied the principles for authoring review articles delineated within the Journal of Medical Toxicology when feasible and appropriate during the review process [60].

\section{Findings}

Our search terms identified 1058 potential articles in PubMed and 721 potential articles in Embase. The review of conference abstracts yielded additional potential cases as follows: ACMT Annual Scientific Meeting (49; original research first reported at this conference in 2011), NACCT (235; abstracts available from 1997 to 2019), ACEP Scientific Assembly (9; data missing for 1993, 1995, 1996), SAEM Annual Meeting (34), AAP National Conference \& Exhibition (0; abstracts available from 2010 to 2018), and the PAS Meeting (0; abstracts available from 2017 to 2019). The FDA's "Drug Alerts and Statements" repository contained an additional 19 reports related to non-hospital-based compounding pharmacies. Through the database searches, two pre-existing reviews of compounding contamination errors were identified, by Staes et al. in 2013 and Shehab et al. in 2018; these respectively identified 11 and 19 cases [61, 62]. In total, a total of 2155 articles, statements, and reports were identified and underwent our manual review (performed by CJW and JDW).

After the application of our exclusion criteria, a total of 63 errors were included. These 63 errors are documented as harming 1155 patients. When broken down by type, contamination accounted for 27 errors adversely affecting 1119 patients (Appendix Table 3) and errors in concentration accounted for 21 events adversely affecting 36 patients (Appendix Table 4). There were 15 reports of identified compounding errors which potentially exposed innumerable patients but did not end up causing any known harm; these were predominantly errors of contamination (Appendix Table 5). The number of patients exposed to potential harm cannot be calculated based on the available data, but reaches at least the several thousands (Framingham alone exposed 13,534 patients with 753 documented instances of patient harm).

Table 1 is a summary of the 27 included contamination errors. With 1119 patients over 27 errors, the median number of patients affected per error is 8 . The mean number of patients affected per error is 41 ; however, by excluding Framingham, that number is 14 . With 81 deaths over 27 errors, the mean number of fatalities per error is 3 ; however, excluding Framingham drops that number to less than $1(0.65)$. The median number of deaths per error is 0 . Five out of the 27 contamination errors were from intraarticular (including epidural) steroids, and eight of 27 were from medications injected intravitreally. A total of 25 of the 27 errors were from medications administered parenterally, in healthcare settings. Three of 27 were from toxic contamination rather than microbiologic 
Table 1 Summary of contamination errors.

\begin{tabular}{|c|c|c|c|c|c|}
\hline Medication & Number & Route of administration & $\begin{array}{l}\text { Location of } \\
\text { administration }\end{array}$ & Type of contaminant & Deaths \\
\hline \multicolumn{6}{|l|}{ Intraarticular steroids } \\
\hline Betamethasone & 11 patients, 1 error [63] & Epidural and joint injection & Healthcare setting & Microbiologic & 3 \\
\hline Methylprednisolone & $\begin{array}{l}787 \text { patients, } 4 \text { errors }[6,62 \text {, } \\
64-67]\end{array}$ & $\begin{array}{l}\text { Epidural, intraarticular, } \\
\text { intramuscular }\end{array}$ & Healthcare setting & Microbiologic & 65 \\
\hline \multicolumn{6}{|l|}{ Analgesics } \\
\hline $\begin{array}{l}\text { Morphine with clonidine, } \\
\text { bupivacaine }\end{array}$ & 8 patients, 1 error [68] & Intrathecal & Healthcare setting & $\begin{array}{l}\text { Methadone, ethanol, } \\
\text { methanol }\end{array}$ & 0 \\
\hline Fentanyl & 15 patients, 2 errors $[69,70]$ & Intravenous & Healthcare setting & Microbiologic & 1 \\
\hline \multicolumn{6}{|l|}{ Ophthalmologic agents } \\
\hline Tryptan blue & 6 patients, 1 error [71] & Intravitreal & Healthcare setting & Microbiologic & 0 \\
\hline Bevacizumab & $\begin{array}{l}34 \text { patients, } 5 \text { errors } \\
{[72-76]}\end{array}$ & Intravitreal & Healthcare setting & Microbiologic & 0 \\
\hline $\begin{array}{l}\text { Brilliant blue green \& } \\
\text { triamcinolone }\end{array}$ & 47 patients, 1 error [77] & Intravitreal & Healthcare setting & Microbiologic & 0 \\
\hline $\begin{array}{l}\text { Triamcinolone \& } \\
\text { moxifloxacin }\end{array}$ & 43 patients, 1 error [78] & Intravitreal & Healthcare setting & Microbiologic & 0 \\
\hline Heparin-vancomycin solution & 2 patients, 1 error [79] & Intravenous & Healthcare setting & Microbiologic & 0 \\
\hline Cardioplegia solution & 11 patients, 1 error $[80,81]$ & Coronary infusion & Healthcare setting & Microbiologic & 3 \\
\hline Heparin-saline solution & 80 patients, 1 error [82] & Intravenous & Healthcare setting & Microbiologic & 0 \\
\hline Magnesium sulfate & 19 patients, 1 error [83] & Intravenous & Healthcare setting & Microbiologic & 0 \\
\hline Parenteral nutrition & 19 patients, 1 error [84] & Intravenous & Healthcare setting & Microbiologic & 9 \\
\hline Methylcobalamin & 6 patients, 1 error [85] & Intravenous & Healthcare setting & Microbiologic & 0 \\
\hline Calcium gluconate & 15 patients, 1 error [86] & Intravenous & Healthcare setting & Microbiologic & 0 \\
\hline Omeprazole & 1 patient, 1 error [87] & Oral & Home & Baclofen & 0 \\
\hline Biotin & 2 patients, 1 error $[88]$ & Oral & Unknown & 4-aminopyridine & 0 \\
\hline $\begin{array}{l}\text { Human chorionic } \\
\text { gonadotropin }\end{array}$ & 6 patients, 1 error [89] & Intramuscular & Healthcare setting & Microbiologic & 0 \\
\hline Glutathione & 7 patients, 1 error $[90]$ & Intravenous & Healthcare setting & Microbiologic & 0 \\
\hline Total & 1119 patients, 27 errors & & & & 81 deaths \\
\hline
\end{tabular}

contamination. Interestingly, six of 27 errors with documented adverse outcomes occurred following the CQA.

Table 2 is a summary of the 21 included sub- and supratherapeutic errors. One report describes a subtherapeutic error affecting 9 pediatric patients who were on posttransplant immunosuppression with tacrolimus. The remaining 20 reports involved errors of supratherapeutic drug concentrations; they affected a total of 27 patients, of which 14 $(52 \%)$ were pediatric. Of the 36 total patients affected by concentration errors, $23(64 \%)$ were pediatric and $3(8 \%)$ were over the age of 65 years. Three patients died, all of whom received supratherapeutic intravenous colchicine at an alternative medicine infusion clinic for chronic back pain [91].

Appended to this article are Appendix Tables 3, 4, 5, which respectively catalog all contamination errors causing patient harm, all sub- and suprapotency errors causing patient harm, and all potential compounding errors identified and rectified before patient harm occurred. Of the 15 potential errors identified before patient harm occurred, 13 came after the enactment of the CQA.

\section{Discussion}

In this study, we separated compounding errors into the categories of contamination, suprapotency, and subpotency. We found that medications with contamination errors are frequently (1) bulkproduced and distributed, (2) used parenterally, and (3) administered by physicians. Because of their parenteral administration, medications contaminated with otherwise benign environmental flora are able to disseminate throughout the body and cause the devastating outcomes documented here. Furthermore, because contamination errors are often associated with larger - even multistate - distribution networks, the reach of their impact is large.

Framingham was the archetypal contamination error. It woke much of the medical and lay communities to the potential dangers of compounding. It inspired the federal government to enact the CQA in 2013 and create an entirely new form of compounding facility - the outsourcing facility- to attempt to regulate the subsection of pharmacies who were bulk-compounding medications not available (or not available cheaply) through commercial channels, and who exported 
Table 2 Summary of subtherapeutic and supratherapeutic error.

\begin{tabular}{|c|c|c|c|c|c|c|}
\hline Medication & Number & Patient age $<18$ years & Patient age $\geq 65$ years & Administered at home & ICU admission & Deaths \\
\hline Tacrolimus & 9 patients, 1 error [93] & $9 / 9$ & $0 / 9$ & $9 / 9$ & Unknown & Unknown \\
\hline Clonidine & 6 patients, 5 errors [106-110] & $6 / 6$ & $0 / 6$ & $6 / 6$ & 3 & 0 \\
\hline 4-Aminopyridine & 4 patients, 3 errors [111-113] & $0 / 4$ & $0 / 4$ & $4 / 4$ & 2 & 0 \\
\hline Liothyronine & 4 patients, 3 errors [114-116] & $0 / 4$ & $1 / 4$ & $4 / 4$ & 3 & 0 \\
\hline Colchicine & 3 patients, 1 error [91] & $0 / 3$ & $1 / 3$ & $0 / 3$ & 3 & 3 \\
\hline Morphine & 3 patients, 1 error [95] & $3 / 3$ & $0 / 3$ & $0 / 3$ & 1 & 0 \\
\hline Atropine & 2 patients, 2 errors $[117,118]$ & $0 / 2$ & $1 / 2$ & $2 / 2$ & 1 & 0 \\
\hline Atenolol & 1 patient, 1 error [119] & $1 / 1$ & $0 / 1$ & $1 / 1$ & 0 & 0 \\
\hline Flecainide & 1 patient, 1 error [120] & $1 / 1$ & $0 / 1$ & $1 / 1$ & 1 & 0 \\
\hline Hydrocortisone & 1 patient, 1 error [121] & $1 / 1$ & $0 / 1$ & $1 / 1$ & 0 & 0 \\
\hline Pyrimethamine & 1 patient, 1 error [122] & $1 / 1$ & $0 / 1$ & $1 / 1$ & 0 & 0 \\
\hline Phenytoin & 1 patient, 1 error [123] & $1 / 1$ & $0 / 1$ & $1 / 1$ & 1 & 0 \\
\hline Total & 36 patients, 21 errors & 23 patients, 11 errors & 3 patients, 3 errors & $30 / 36$ & $15 / 27^{*}$ & $3 / 27 *$ \\
\hline
\end{tabular}

*Number of ICU admissions and deaths from 9 tacrolimus patients unknown therefore not included

those medications across state lines to be used on countless patients in several healthcare settings. We do not have FDA alert archives dating prior to 2010, but we have identified over a dozen instances post-CQA where FDA inspections have identified outsourcing facilities at risk for distributing contaminated medications despite their expected adherence to CGMP standards. While this FDA oversight is clearly needed, it is likely not sufficiently robust. For example, no budgetary allocation was initially made to support oversight in the CQA's establishment of outsourcing facilities [46]. FDA Commissioner Scott Gottleib, in 2018 Congressional testimony, highlighted the funding struggles affecting oversight, stating "I don't want to get too deep into the resource question... [b]ut this is a program where we do operate by in some cases begging, borrowing, and stealing from... other parts of the agency." [45]

Certainly, contamination has persisted despite the CQA and the FDA's efforts to oversee outsourcing facilities. Given this ongoing concern, the medical community must bear some of the responsibility for reducing the number of medications manufactured in substandard environments. It should be the expected standard for healthcare practices to purchase exclusively from compounding pharmacies strictly adherent to CGMP standards and formally approved as outsourcing facilities by the FDA. Leading expert Outterson referenced the potential for this approach in 2014 [46], and it is unclear how purchasers have responded. While these policies may be more expensive; the physical, ethical, and even financial [92] consequences of purchasing compounded medications from organizations not sufficiently invested in safety are clearly documented here.

Subpotency and suprapotency can be considered as the single category of errors of concentration, as the sources and scope of concentration errors are largely similar. Our findings demonstrate that subpotency is largely not a reportable issue, but that does not mean it is not a danger. As an example, beyond the cited series of subtherapeutic tacrolimus concentrations [93], another case series (excluded for location outside the US) identifies dozens of patients who received subtherapeutic chemotherapy treatments [94]. These subtherapeutic errors are difficult to capture. Identification must be done during routine serum testing, as occurred with the tacrolimus series; or on the supply side, as occurred with the chemotherapy series. When considering subtherapeutic and supratherapeutic errors together as errors of concentration, we found a somewhat different pattern than that which we identified amongst errors of contamination. The concentration errors we were able to identify, with a few notable exceptions $[95,96]$, were caused by traditional compounding pharmacies. These pharmacies, labeled as 503A pharmacies under the $\mathrm{CQA}$, are limited in their scope to producing compounded medications only after an individual prescription is in-hand. Per the CQA, 503A pharmacies are still solely regulated by state boards of pharmacy, meaning that oversight is patchwork across the US. Many concentration errors are of orders of magnitude, suggesting that simple mathematical and measurement mistakes are to blame. In addition to hoping that states will implement greater oversight of these 503A pharmacies, we call on the pharmacy industry to emphasize and standardize compounding training amongst its students and even consider a mandatory credential before allowing a pharmacist or pharmacy technician to compound a medication [26, 97-99].

It is worth noting that 4-aminopyridine and liothyronine are fairly uncommon medications, however they accounted for a large number of compounding concentration errors. There is nothing particularly special about these 
medications which make them prone to concentration errors, except for the fact that they are not readily commercially available, and so they must be compounded. The prescribers of these medications need to carefully consider the benefits and risks of prescribing a treatment which requires compounding; especially when the risks are so great (status epilepticus with 4-aminopyridine and thyrotoxicosis with liothyronine). Liothyronine, in particular, has had its clinical utility recently questioned. For example, the National Health Service (UK) has recently called on general practitioners to stop prescribing liothyronine without specialist consultation, as most patients benefit equally from commercially prepared levothyroxine [100]. Given the risks of inadvertent overdose due to compounding errors, providers must consider commercially available alternatives whenever able. In fact, it has been questioned whether providers who knowingly prescribe a compounded medication despite commercially available alternatives might be legally liable for any harm resulting from compounding errors [101]. At the very least, it is incumbent on prescribers as well as pharmacists to educate their patients on the risks of taking a compounded medication-both from errors in concentration and contamination - and to instruct them on when to present to a healthcare provider. Additionally, practitioners must be aware of their patients' medication lists, and consider a possible compounding error as a cause of medical illness. Notably, we found that the majority of concentration errors were made in pediatric and geriatric patients, vulnerable populations who are already at increased risk of providers failing to diagnose toxicity from prescription medications.

In 2020 and beyond, we anticipate the demand for compounding to only increase. The number of novel therapeutics continues to rise rapidly, as do their approved routes of administration. The anti-angiogenesis medication bevacizumab is a classic example; it is commercially manufactured but is frequently compounded into smaller aliquots for intravitreal administration. As we have seen, this process has unfortunately resulted in multiple outbreaks of endophthalmitis [72-76]. Furthermore, regional and global disasters have recently resulted in significant pharmaceutical supply chain issues. Examples of this phenomenon include Hurricane Maria's impact on Puerto Rican manufacturers in 2017 and the COVID-19 pandemic [120-123]. These disruptions place increased demand on alternative means of supply, including via pharmaceutical compounding. In fact, the COVID-19 pandemic and its associated drug shortages has already resulted in the loosening of FDA restrictions, including allowing outsourcing facilities to compound copies of commercially available drugs for hospital use [21].

Our study has its limitations. While we made every effort to capture published cases of compounding errors, it is possible that our search criteria missed some cases that would have impacted our analyses. While we also strove to review less-traditional sources, including conference abstracts and FDA alerts, we are not free of publication bias and are at risk for having excluded compounding errors not associated with adverse events, or with very small numbers of patients affected. Similarly, it must be noted that compounding errors can only be identified following adverse events, laboratory screening, or industry or governmental report. Even once identified, we were dependent on the publication of the error in order to capture it here. As such, we are likely underreporting the frequency with which compounding errors occur.

\section{Conclusions}

Compounding is more relevant than ever. Appreciating that the need for compounding is unlikely to diminish in the near future, we can only re-emphasize the critical nature of our recommendations for the federal and state governments to fully fund the oversight of outsourcing facilities, for healthcare practices to refuse medications compounded without strict adherence to CGMP and FDA regulations, for pharmacy schools to expand compounding training and certification, and for physicians to think critically about the risks of prescribing medications that are not commercially produced. Conversely, we must remain aware that compounding pharmacies frequently provide an essential service and poorly calibrated regulations may contribute to issues of access. Ultimately, medical providers must remain vigilant, especially when caring for members of vulnerable populations, and consider the possibility that a new-onset illness may very well be the result of a compounding error.

Acknowledgments We gratefully acknowledge the contributions of Shannon Manzi, PharmD, Assistant Professor of Pediatrics at Harvard Medical School and Manager of the Boston Children's Hospital Emergency Department and Intensive Care Unit Pharmacy Services, to this manuscript.

Author Contributions Study concept and design: CJW, JDW, AMS, MMB

Acquisition of the data: CJW, JDW

Analysis and interpretation of the data: CJW, JDW, AMS, MMB

Drafting of the manuscript: CJW, JDW, AMS, MMB

Critical revision of the manuscript: CJW, JDW, AMS, MMB

\section{Compliance with Ethical Standards}

Conflict of Interest CJW, JDW, and AMS report no conflicts of interest. MMB reports that she is the Pediatric Toxicology Section Editor at UpToDate. 


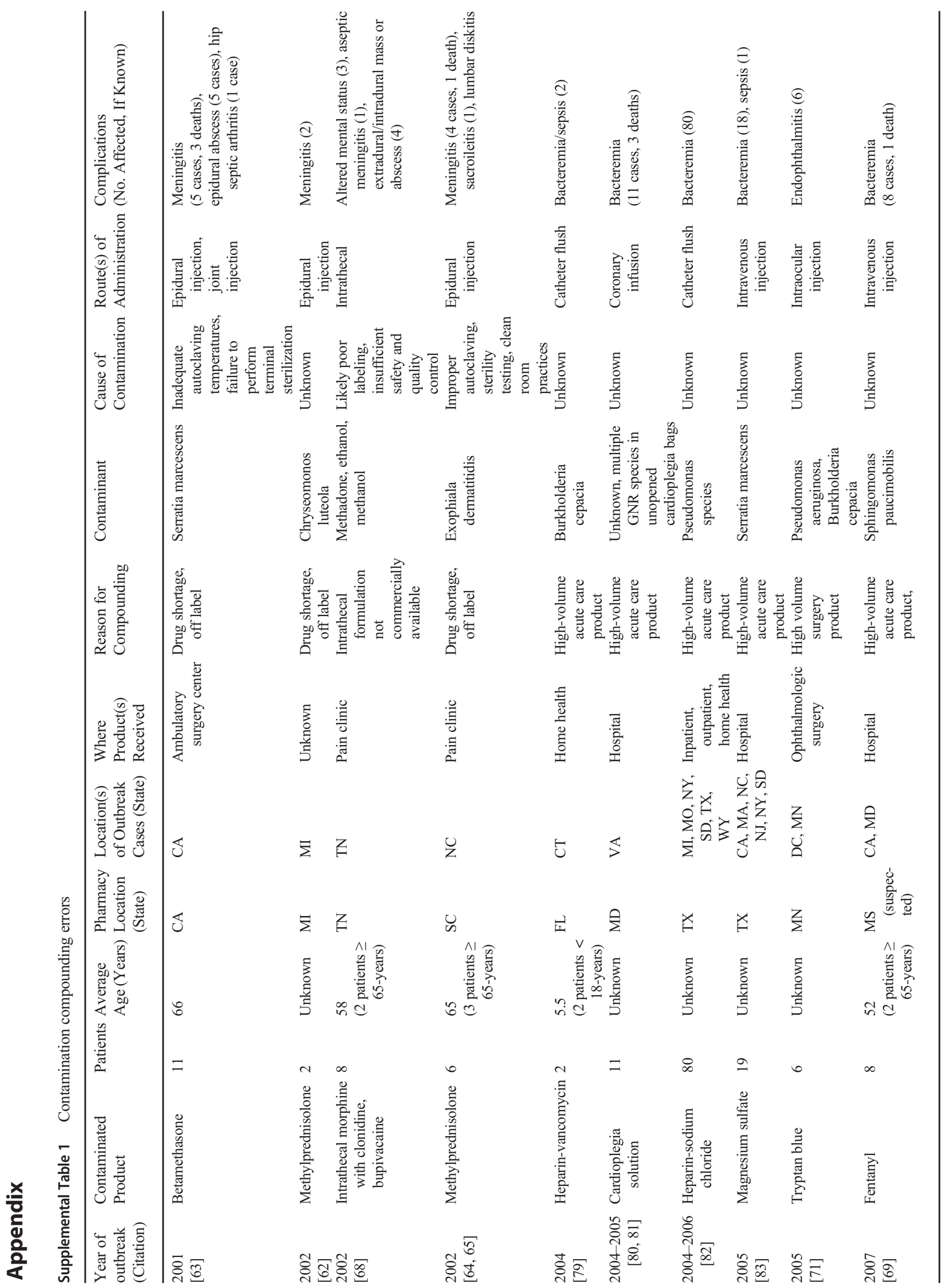




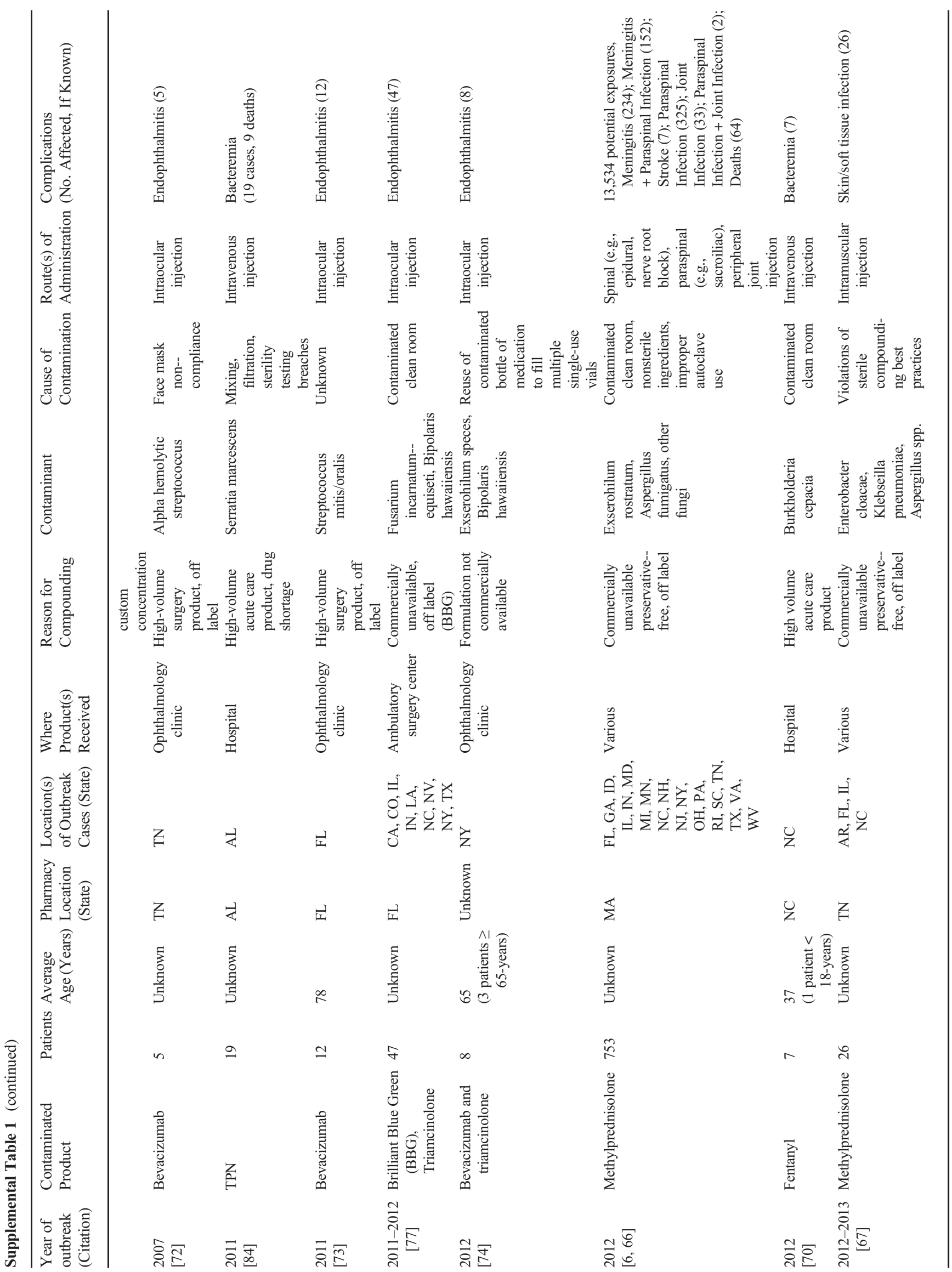




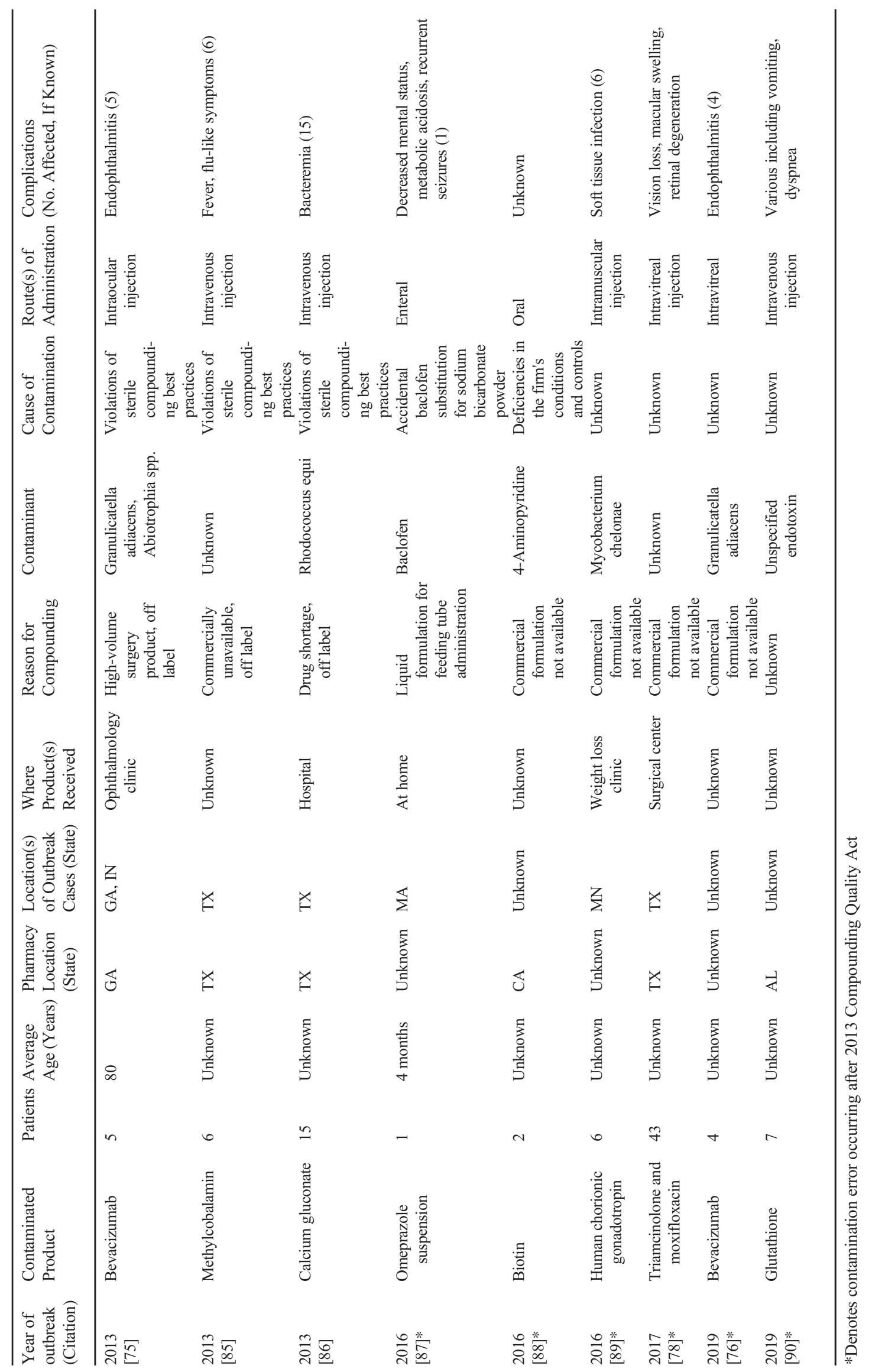




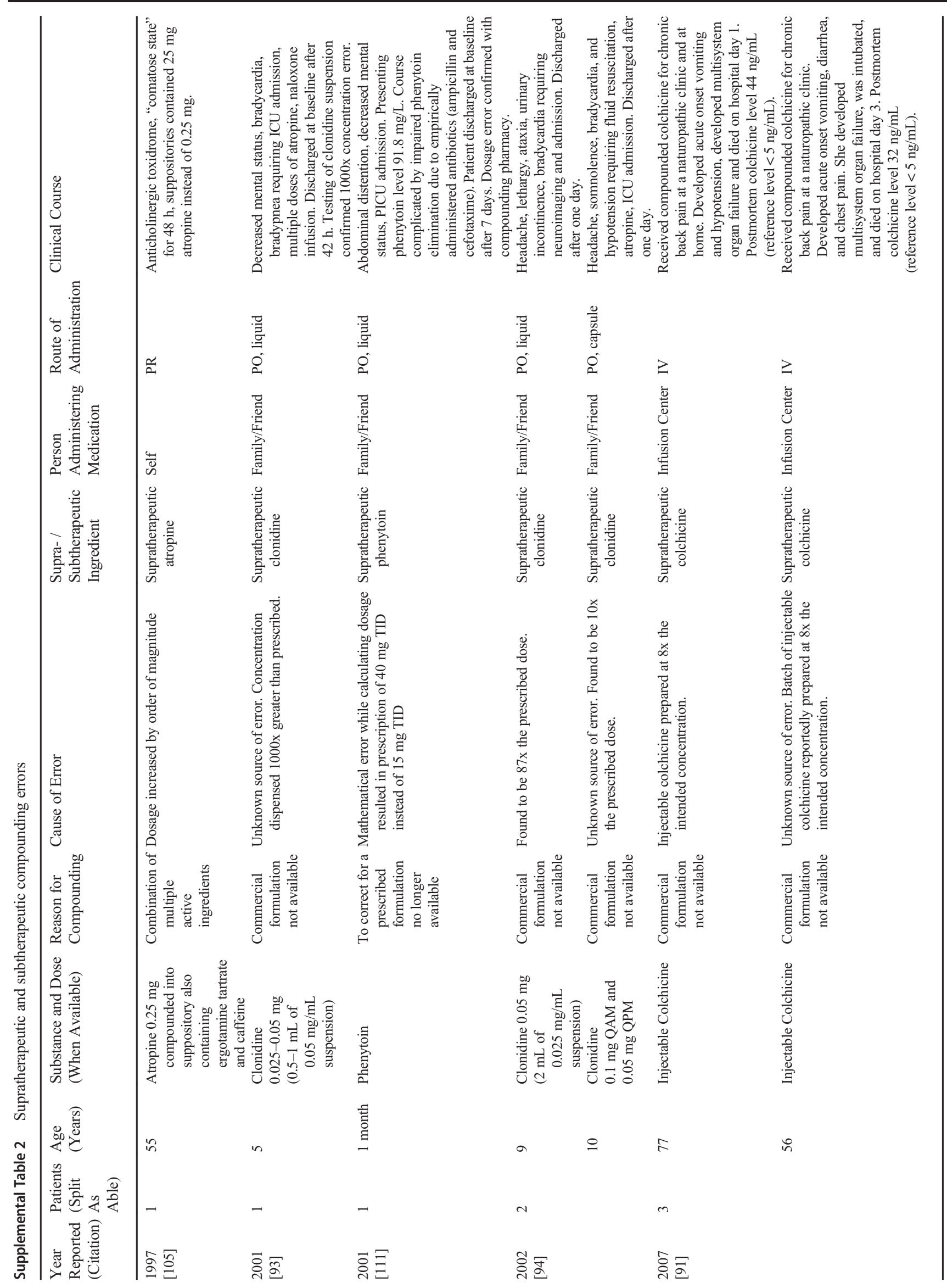




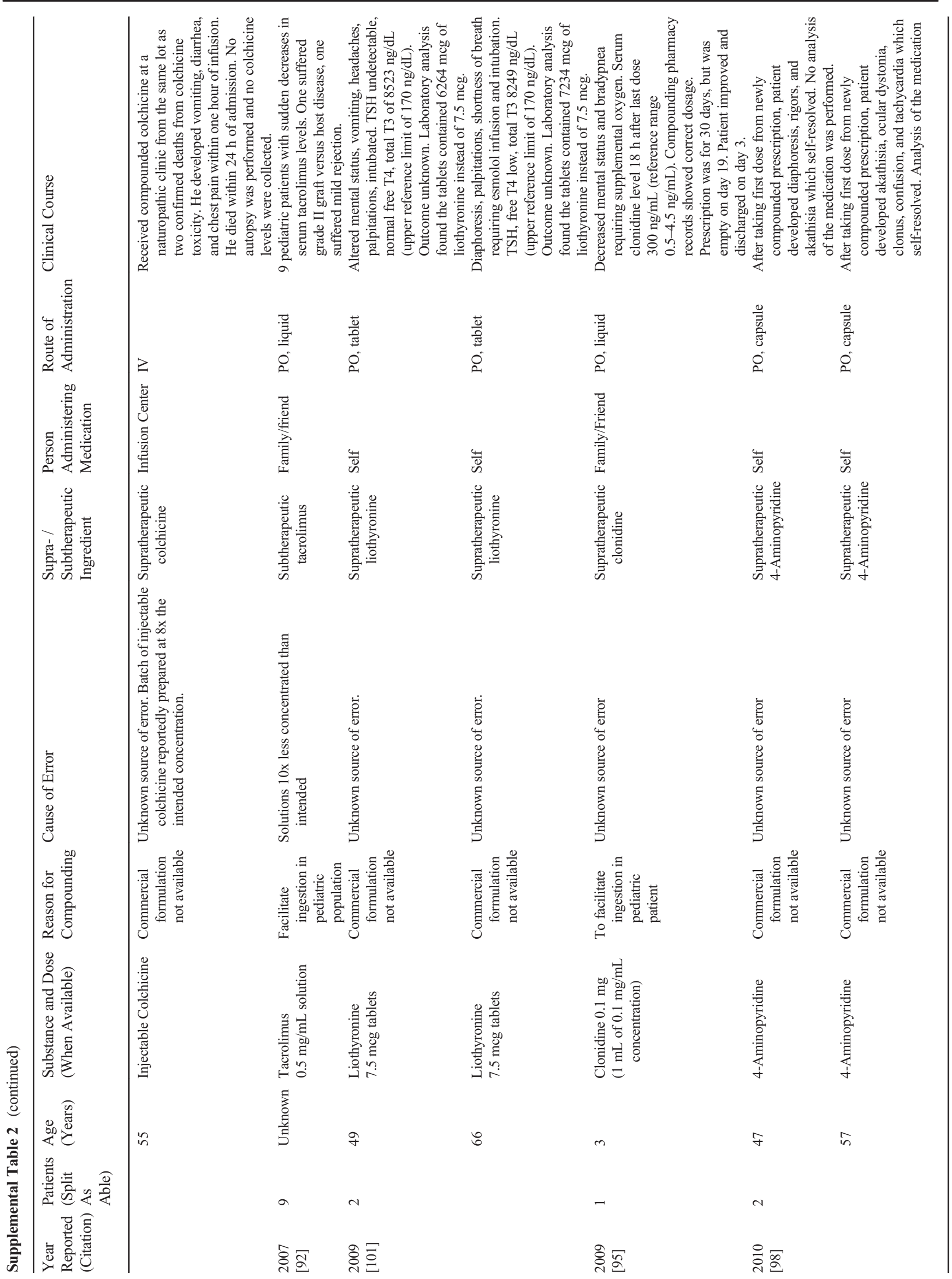




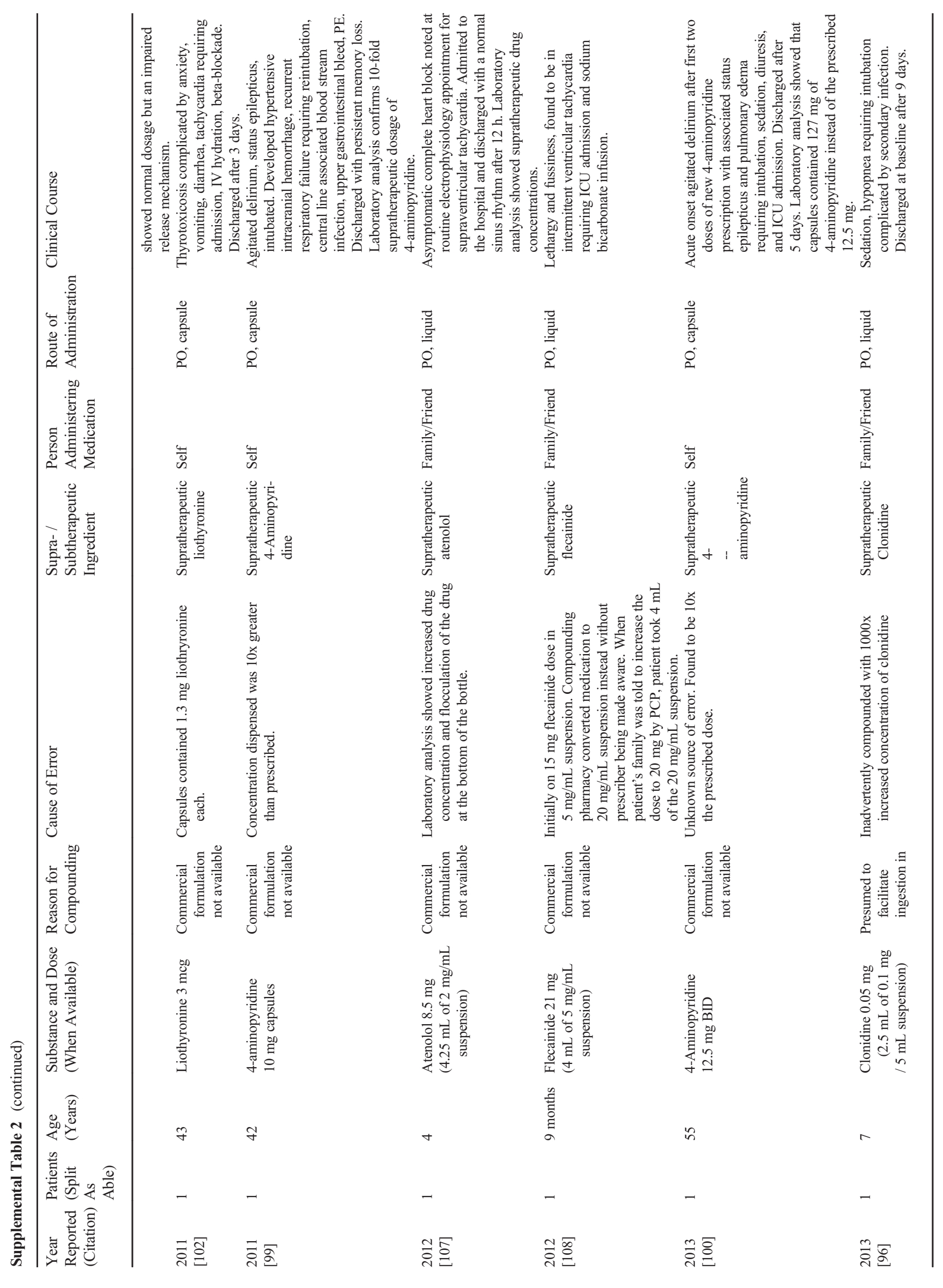




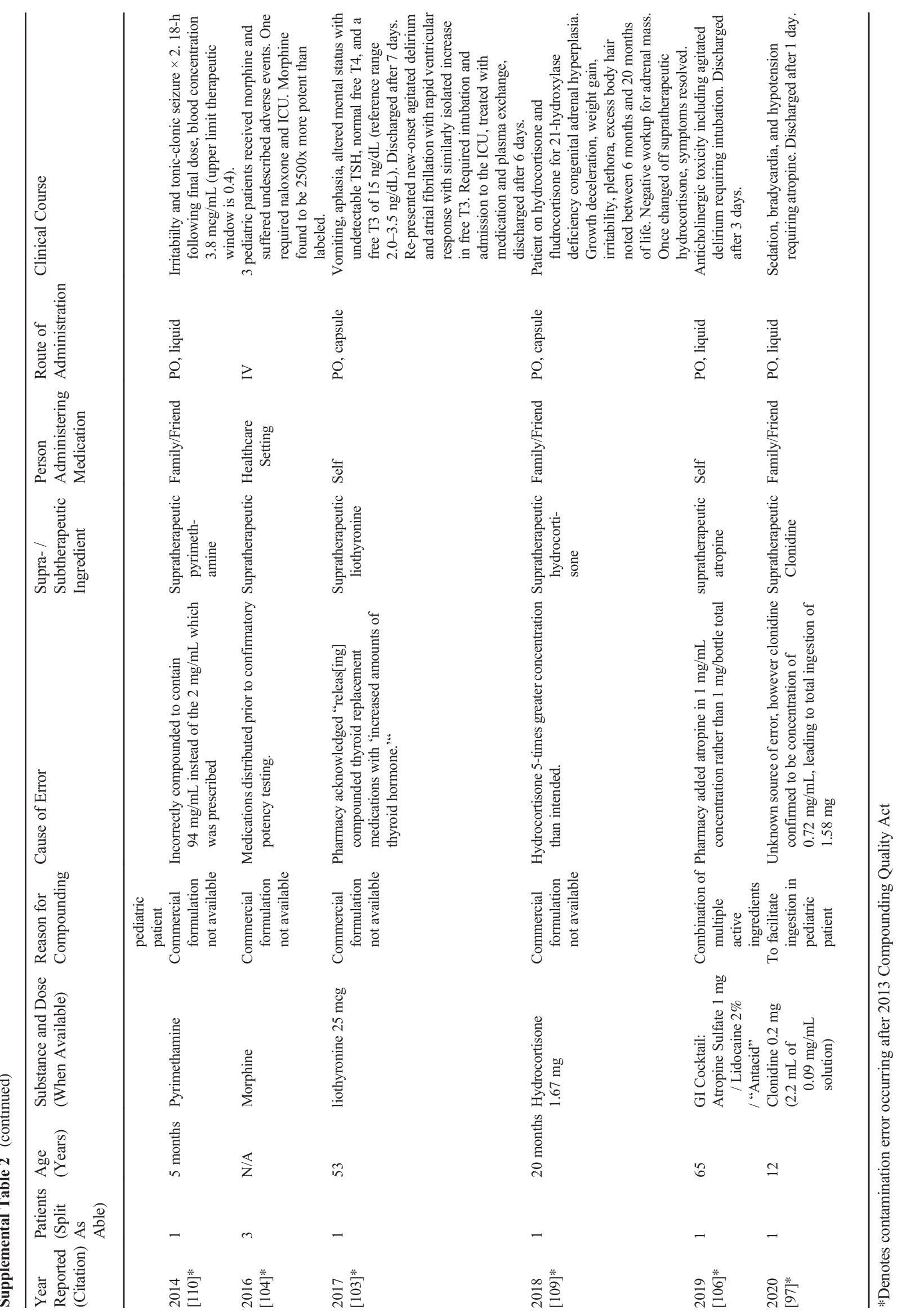


Supplemental Table 3 Compounding pharmacy errors without documented patient harm.

\begin{tabular}{|c|c|c|c|}
\hline $\begin{array}{l}\text { Pharmacy Involved } \\
\text { and Year Reported } \\
\text { (Citation) }\end{array}$ & Event & Medication & $\begin{array}{l}\text { Documented Pharmacy Action } \\
\text { Adverse } \\
\text { Events }\end{array}$ \\
\hline
\end{tabular}

\begin{tabular}{|c|c|c|c|c|}
\hline $\begin{array}{l}\text { The Compounding Shop } 2013 \\
\text { [124] }\end{array}$ & $\begin{array}{l}\text { Through unknown means, FDA identified that } \\
\text { compounded inhaled budesonide was } \\
\text { contaminated with fungus }\end{array}$ & Budesonide & None & Recall recommended, not initiated \\
\hline $\begin{array}{l}\text { Unknown Pharmacy } 2013 \\
\text { [112] }\end{array}$ & $\begin{array}{l}1309 \text { potential in-hospital exposure exposures to } \\
\text { magnesium sulfate contaminated with multiple } \\
\text { fungal species, no documented infections }\end{array}$ & $\begin{array}{l}\text { Magnesium } \\
\text { Sulfate }\end{array}$ & None & Unknown \\
\hline $\begin{array}{l}\text { Downing Labs, } \\
2014[125]^{*}\end{array}$ & $\begin{array}{l}\text { On inspection, FDA identified insufficient sterility } \\
\text { measures at compounding facility }\end{array}$ & Multiple & None & No recall \\
\hline $\begin{array}{l}\text { Medistat RX } 2015 \\
{[126]^{*}}\end{array}$ & $\begin{array}{l}\text { On inspection, FDA identified insufficient sterility } \\
\text { measures at compounding facility }\end{array}$ & Multiple & None & Voluntary recall \\
\hline $\begin{array}{l}\text { Qualgen } 2015 \\
{[127]^{*}}\end{array}$ & $\begin{array}{l}\text { On inspection, FDA identified insufficient sterility } \\
\text { measures at compounding facility }\end{array}$ & Multiple & None & Recall recommended, not initiated \\
\hline $\begin{array}{l}\text { Glades } 2015 \\
{[114]^{*}}\end{array}$ & $\begin{array}{l}\text { FDA notified of "several" adverse events } \\
\text { involving supratherapeutic Vitamin D; events } \\
\text { not documented or enumerated }\end{array}$ & Vitamin D3 & Unknown & Voluntary recall \\
\hline $\begin{array}{l}\text { Medaus } 2016 \\
{[128]^{*}}\end{array}$ & $\begin{array}{l}\text { On inspection, FDA identified insufficient sterility } \\
\text { measures at compounding facility }\end{array}$ & Multiple & None & $\begin{array}{l}\text { Ordered to cease sterile } \\
\text { pharmaceutical compounding, did } \\
\text { not comply with recommendation } \\
\text { for recall }\end{array}$ \\
\hline $\begin{array}{l}\text { Pharmakon, } \\
2016[129]^{*}\end{array}$ & $\begin{array}{l}\text { On inspection, FDA identified insufficient sterility } \\
\text { measures at compounding facility }\end{array}$ & Multiple & None & Voluntary recall \\
\hline $\begin{array}{l}\text { Atlantic Pharmacy } 2017 \\
{[130]^{*}}\end{array}$ & $\begin{array}{l}\text { On inspection, FDA identified insufficient sterility } \\
\text { measures at compounding facility }\end{array}$ & Multiple & None & Recall recommended, not initiated \\
\hline $\begin{array}{l}\text { Coastal Meds } 2018 \\
{[131]^{*}}\end{array}$ & $\begin{array}{l}\text { On inspection, FDA identified insufficient sterility } \\
\text { measures at compounding facility }\end{array}$ & Multiple & None & Voluntary recall \\
\hline $\begin{array}{l}\text { Ranier's Rx } 2018 \\
{[132]^{*}}\end{array}$ & $\begin{array}{l}\text { On inspection, FDA identified insufficient sterility } \\
\text { measures at compounding facility }\end{array}$ & Multiple & None & Voluntary recall \\
\hline $\begin{array}{l}\text { Pharm D } 2018 \\
{[133]^{*}}\end{array}$ & $\begin{array}{l}\text { On inspection, FDA identified insufficient sterility } \\
\text { measures at compounding facility }\end{array}$ & Multiple & None & Partial voluntary recall \\
\hline $\begin{array}{l}\text { Promise Pharmacy } 2018 \\
{[134]^{*}}\end{array}$ & $\begin{array}{l}\text { On inspection, FDA identified insufficient sterility } \\
\text { measures at compounding facility }\end{array}$ & Multiple & None & Partial voluntary recall \\
\hline $\begin{array}{l}\text { Infusion Options } 2019 \\
{[135]^{*}}\end{array}$ & $\begin{array}{l}\text { On inspection, FDA identified insufficient sterility } \\
\text { measures at compounding facility }\end{array}$ & Multiple & None & Voluntary recall \\
\hline $\begin{array}{l}\text { AmEx Pharmacy } 2019 \\
{[136]^{*}}\end{array}$ & $\begin{array}{l}\text { On inspection, FDA identified insufficient sterility } \\
\text { measures at compounding facility }\end{array}$ & Multiple & None & Voluntary recall \\
\hline
\end{tabular}

*Denotes contamination error occurring after 2013 Compounding Quality Act

\section{References}

1. Young D. Outsourced compounding can be problematic. Am J Health-Syst Pharm. 2002;59:2261-4.

2. Alcorn T. Meningitis outbreak reveals gaps in US drug regulation. Lancet. 2012;380(9853):1543-4.

3. Outterson K. Regulating compounding pharmacies after NECC. N Engl J Med. 2012;367(21):1969-72.

4. Teshome BF, Reveles KR, Lee GC, Ryan L, Frei CR. How gaps in regulation of compounding pharmacy set the stage for a multistate fungal meningitis outbreak. J Am Pharm Assoc. 2014;54(4): 441-5.

5. Kainer MA, Reagan DR, Nguyen DB, Wiese AD, Wise ME, Ward J, et al. Fungal infections associated with contaminated methylprednisolone in Tennessee. N Engl J Med. 2012;367(23): 2194-203.

6. Smith RM, Schaefer MK, Kainer MA, Wise M, Finks J, Duwve J, et al. Fungal infections associated with contaminated methylprednisolone injections. N Engl J Med. 2013;369(17):1598-609.

7. Human drug compounding. U.S. Food \& Drug Administration. December 19, 2019. https://www.fda.gov/drugs/guidance- compliance-regulatory-information/human-drug-compounding. Accessed May 31, 2020.

8. Chapter 795: pharmaceutical compounding - nonsterile preparations. United States Pharmacopeia. January 1, 2014. https://www. uspnf.com/sites/default/files/usp_pdf/EN/USPNF/revisions/ gc795.pdf. Accessed June 29, 2020.

9. Gudeman J, Jozwiakowski M, Chollet J, Randell M. Potential risks of pharmacy compounding. Drugs RD. 2013;13(1):1-8.

10. Guidance For Entities Considering Whether to Register As Outsourcing Facilities Under Section 503B of the Federal Food, Drug, and Cosmetic Act. U.S. Food and Drug Administration. August 2015. https://www.fda.gov/files/drugs/published/ Guidance-For-Entities-Considering-Whether-to-Register-AsOutsourcing-Facilities-Under-Section-503B-of-the-FederalFood\%2D\%2DDrug\%2D\%2Dand-Cosmetic-Act.pdf. Accessed June 29, 2020

11. Williams NT. Medication administration through enteral feeding tubes. Am J Health Syst Pharm. 2008;65(24):2347-57.

12. Cimolai N. Penicillin VK oral suspension. Can Med Assoc J. 2015;187(6):439.2-439. 
13. Misiewicz Runyon A, So T-Y. The use of ketogenic diet in pediatric patients with epilepsy. ISRN Pediatr. 2012;2012:1-10.

14. Yang X, Fang P, Xiang D, Yang Y. Topical treatments for diabetic neuropathic pain (review). Exp Ther Med. 2019;17:1963-76.

15. Younis US, Fazel M, Myrdal PB. Characterization of tetracycline hydrochloride compounded in a miracle mouthwash formulation. AAPS PharmSciTech. 2019;20(5):1-8.

16. DeLegge $\mathrm{MH}$. Parenteral nutrition therapy over the next 5-10 years: where are we heading? J Parenter Enter Nutr. 2012;36(Supplement 2):56S-61S.

17. Gilbert RE, Kozak MC, Dobish RB, Bourrier VC, Koke PM, Kukreti V, et al. Intravenous chemotherapy compounding errors in a follow-up pan-Canadian observational study. J Oncol Pract. 2018;14(5):e295-303.

18. Sklenar Z, Scigel V, Horackova K, Slanar O. Compounded preparations with nystatin for oral and oromucosal administration. Acta Poloniae Pharmaceutica - Drug Research. 2013;70(4):75962.

19. Guharoy R, Noviasky J, Haydar Z, Fakih MG, Hartman C. Compounding pharmacy conundrum. Chest. 2013;143(4):896900 .

20. Barrera K, McNicoll C, Sangji N. Drug shortages: the invisible epidemic. Bulletin of the American College of Surgeons November 1, 2018. https://bulletin.facs.org/2018/11/drugshortages-the-invisible-epidemic/. Accessed June 29, 2020.

21. Temporary policy for compounding of certain drugs for hospitalized patients by pharmacy compounders not registered as outsourcing facilities during the COVID-19 public health emergency (revised): guidance for industry. United States Food and Drug Administration. May 21, 2020. https://www.fda.gov/ media/137125/download. Accessed June 29, 2020.

22. Compounding activities: COVID-19. U.S. Food \& Drug Administration. April 7, 2020. https://www.fda.gov/drugs/ coronavirus-covid-19-drugs/compounding-activities-covid-19. Accessed June 29, 2020.

23. Chapter 797: pharmaceutical compounding - sterile preparations. United States Pharmacopeia. June 1, 2008. https://www.sefh.es/ fichadjuntos/USP797GC.pdf. Accessed June 29, 2020.

24. Allen L. Guidelines for compounding practices. In: The art, Science, and Technology of Pharmaceutical Compounding. 4th ed. Washington, DC: American Pharmacists Association; 2012. p. $1-18$.

25. Mullarkey T. Pharmacy compounding of high-risk level products and patient safety. Am J Health Syst Pharm. 2009;66(17_Supplement_5):S4-S13.

26. Kochanowska-Karamyan AJ. Pharmaceutical compounding: the oldest, most symbolic, and still vital part of pharmacy. Int J Pharm Compd. 2016;20(5):367-74

27. Urick BY, Meggs EV. Towards a greater professional standing: evolution of pharmacy practice and education, 1920-2020. Pharmacy. 2019;7(3):98.

28. Higby GJ. The continuing evolution of American pharmacy practice, 1952-2002. J Am Pharm Assoc 1996. 2002;42(1):12-15.

29. Cantrell SA. Improving the quality of compounded sterile drug products: a historical perspective. Ther Innov Regul Sci. 2016;50(3):266-9.

30. Grober ED, Garbens A, Božović A, Kulasingam V, Fanipour M, Diamandis EP. Accuracy of testosterone concentrations in compounded testosterone products. J Sex Med. 2015;12(6): $1381-8$.

31. Pinkerton JV, Pickar JH. Update on medical and regulatory issues pertaining to compounded and FDA-approved drugs, including hormone therapy. Menopause. 2016;23(2):215-23.

32. Boodoo JM. Compounding problems and compounding confusion: federal regulation of compounded drug products and the FDAMA circuit split. Am J Law Med. 2010;36:220-47.
33. Drazen JM, Curfman GD, Baden LR, Morrissey S. Compounding errors. N Engl J Med. 2012;367(25):2436-7.

34. Kainer M, Wiese AD, Benedict K, et al. Multistate outbreak of fungal infection associated with injection of methylprednisolone acetate solution from a single compounding pharmacy - United States, 2012. MMWR Morb Mortal Wkly Rep. 2012;61(41):83942.

35. Multistate outbreak of fungal meningitis and other infections. United States Centers for Disease Control and Prevention. October 30, 2015. https://www.cdc.gov/hai/outbreaks/ meningitis.html. Accessed June 2, 2020.

36. Abbas KM, Dorratoltaj N, O’Dell ML, Bordwine P, Kerkering TM, Redican KJ. Clinical response, outbreak investigation, and epidemiology of the fungal meningitis epidemic in the United States: systematic review. Disaster Med Public Health Prep. 2016;10(1):145-51.

37. Goldman TR. Health policy brief: regulating compounding pharmacies. Health Aff May. 2014;1.

38. Drug compounding: FDA has taken steps to implement compounding law, but some states and stakeholders reported challenges. United States Government Accountability Office. November 2016. https://www.gao.gov/products/GAO-17-64. Accessed June 29, 2020.

39. Federal Food, Drug, and Cosmetic Act, 21 USC $\S \S 301-399 i$ (2018).

40. Nolan A. Federal authority to regulate the compounding of human drugs. Congressional Research Service April 12, 2013. https://fas. $\mathrm{org} / \mathrm{sgp} / \mathrm{crs} / \mathrm{misc} / \mathrm{R} 43038 . p d f$. Accessed June 29, 2020.

41. Food and Drug Administration Modernization Act of 1997, 21 USC $§ 353$ a (2018).

42. Thompson v Western States Medical Center. 535 US 357, 368-78 (2002).

43. The Drug Quality and Security Act, 21 USC \$331-379j-62 (2018).

44. The Proposed Drug Quality and Security Act (H.R. 3204). Congressional Research Service. October 31, 2013. https:/ www.everycrsreport.com/files/20131031 R43290 b736047f7532e678fb6793b144115d837c6029a4.pdf. Accessed May 14, 2020.

45. Examining Implementation of the Compounding Quality Act, Hearing before the Subcommittee on Health of the House Committee on Energy and Commerce. 115th Cong, 2nd Sess (2018) (testimony of Scott Gottlieb, (former) Commissioner of FDA).

46. Outterson $\mathrm{K}$. The drug quality and security act - mind the gaps. N Engl J Med. 2014;370(2):97-9.

47. 21 USC $\$ 353 \mathrm{a}$ (2018).

48. 21 USC $\$ 353 a(a)-(b)(2018)$.

49. 21 USC $\$ 353 b$ (2018).

50. Human drug compounding outsourcing facility fees. United States Food and Drug Administration. August 12, 2019. https://www. fda.gov/industry/fda-user-fee-programs/human-drugcompounding-outsourcing-facility-fees. Accessed May 25, 2020.

51. Palumbo FB, Rosebush LH, Zeta LM. Navigating through a complex and inconsistent regulatory framework: section 503B of the Federal Food Drug and Cosmetic Act outsourcing facilities engaged in clinical investigation. Ther Innov Regul Sci. 2016;50(3):270-8

52. State oversight of drug compounding. Pew Charitable Trust. February 2018. https://www.pewtrusts.org/en/research-andanalysis/reports/2018/02/state-oversight-of-drug-compounding. Accessed May 15, 2020.

53. U.S. FDA. 2018 Compounding policies priorities plan. https:// www.fda.gov/drugs/human-drug-compounding/ 2018 compounding-policy-priorities-plan. Published January 2018. Current as of June 21, 2018. Accessed May 25, 2020. 
54. Human Drug Compounding Under Sections 503A and 503B of the Federal Food, Drug, and Cosmetic Act. Fed Regist. 2020; 85 FR 28961: 28961-28965. https://www.federalregister.gov/ documents/2020/05/14/ 2020-10336/agency-informationcollection-activities-submission-for-office-of-management-andbudget-review. Accessed June 28, 2020.

55. 21 USC § 353a(b)(3)(B)(i)-(ii) (2018).

56. Registered outsourcing facilities. United States Food and Drug Administration. May 13, 2020. https://www.fda.gov/drugs/ human-drug-compounding/registered-outsourcing-facilities. Accessed May 25, 2020.

57. Current good manufacturing practice - guidance for human drug compounding outsourcing facilities under Section 503B of the FD\&C Act: guidance for industry. United States Food and Drug Administration. January 20, 2020. https://www.fda.gov /media/ 88905/download. Accessed May 25, 2020.

58. Preserving Patient Access to Compounded Medications Act of 2019, HR 1959, 116th Cong, 2nd Sess (2019).

59. Federal and state role in pharmacy compounding and reconstitution: exploring the right mix to protect patients: Hearing before the Senate Committee on Health, Education, Labor, and Pensions. 108th Cong, 1st Sess (2003) (testimony of Sarah Sellers, PharmD, MPH, executive director, The Center For Pharmaceutical Safety).

60. Murphy CM. Writing an effective review article. J Med Toxicol. 2012;8(2):89-90.

61. Staes C, Jacobs J, Mayer J, Allen J. Description of outbreaks of health-care-associated infections related to compounding pharmacies, 2000-12. Am J Health Syst Pharm. 2013;70(15):1301-12.

62. Shehab N, Brown MN, Kallen AJ, Perz JF. U.S. compounding pharmacy-related outbreaks, 2001-2013: public health and patient safety lessons learned. J Patient Saf. 2018;14(3):164-73.

63. Civen R, Vugia DJ, Alexander R, Brunner W, Taylor S, Parris N, et al. Outbreak of Serratia marcescens infections following injection of betamethasone compounded at a community pharmacy. Clin Infect Dis. 2006;43(7):831-7.

64. Engemann J, Kaye K, Cox G, Perfect J. Exophiala infection from contaminated injectable steroids prepared by a compounding pharmacy - United States, July-November 2002. MMWR Morb Mortal Wkly Rep. 2002;51(49):1109-12.

65. Exophiala dermatitidis Fungal Infection Outbreak. North Carolina Department of Health and Human Services. December 2002. https://epi.dph.ncdhhs.gov/pdf/en2002-4.pdf. Accessed June 29, 2020.

66. Smith RM, Derado G, Wise M, Harris JR, Chiller T, Meltzer MI, et al. Estimated deaths and illnesses averted during fungal meningitis outbreak associated with contaminated steroid injections, United States, 2012-2013. Emerg Infect Dis. 2015;21(6):933-40.

67. Multistate investigation of suspected infections following steroid injections. United States Centers for Disease Control and Prevention. May 30, 2013. https://www.cdc.gov/hai/outbreaks/ TN-pharmacy/index.html. Accessed June 29, 2020.

68. Jones TF, Feler CA, Simmons BP, Melton K, Craig AS, Moore WL, et al. Neurologic complications including paralysis after a medication error involving implanted intrathecal catheters. Am J Med. 2002;112(1):31-6.

69. Maragakis LL, Chaiwarith R, Srinivasan A, Torriani FJ, Avdic E, Lee A, et al. Sphingomonas paucimobilis bloodstream infections associated with contaminated intravenous fentanyl. Emerg Infect Dis. 2009;15(1):12-8.

70. Moehring RW, Lewis SS, Isaacs PJ, Schell WA, Thomann WR, Althaus MM, et al. Outbreak of bacteremia due to Burkholderia contaminans linked to intravenous fentanyl from an institutional compounding pharmacy. JAMA Intern Med. 2014;174(4):60612.
71. Sunenshine R, Schultz M, Lawrence MG, Shin S, Jensen B, Zubairi S, et al. An outbreak of postoperative gram-negative bacterial endophthalmitis associated with contaminated trypan blue ophthalmic solution. Clin Infect Dis. 2009;48(11):1580-3.

72. Frost B, Kainer M. Eye opening: are compounded drugs causing harm? In: Society of Healthcare Epidemiology of America Annual Scientific Meeting; 2011.

73. Goldberg RA, Flynn HW, Isom RF, Miller D, Gonzalez S. An outbreak of Streptococcus endophthalmitis after intravitreal injection of bevacizumab. Am J Ophthalmol. 2012;153(2):204-8.

74. Sheyman AT, Cohen BZ, Friedman AH, Ackert JM. An outbreak of fungal endophthalmitis after intravitreal injection of compounded combined bevacizumab and triamcinolone. JAMA Ophthalmol. 2013;131(7):864-9.

75. Edison LS, Dishman HO, Tobin-D'Angelo MJ, Allen CR, Guh AY, Drenzek CL. Endophthalmitis outbreak associated with repackaged bevacizumab. Emerg Infect Dis. 2015;21(1):171-3.

76. Barnes A, Iyer M, Rathbun S, Yeh S, Bergstrom C, Hubbard GB. Management of a cluster of endophthalmitis cases due to nutritionally variant Streptococcus following intravitreal bevacizumab. In: ARVO Annual Meeting; 2019.

77. Mikosz CA, Smith RM, Kim M, Tyson C, Lee EH, Adams E, et al. Fungal endophthalmitis associated with compounded products. Emerg Infect Dis. 2014;20(2):248-56.

78. FDA alerts health care professionals of adverse events associated with Guardian's compounded triamcinolone and moxifloxacin product for intravitreal injection. United States Food and Drug Administration. July 28, 2017. https://www.fda.gov/drugs/drugsafety-and-availability/fda-alerts-health-care-professionalsadverse-events-associated-guardians-compounded-triamcinolone. Accessed June 29, 2020.

79. Held MR, Begier EM, Beardsley DS, Browne FA, Martinello RA, Baltimore RS, et al. Life-threatening sepsis caused by Burkholderia cepacia from contaminated intravenous flush solutions prepared by a compounding pharmacy in another state. Pediatrics. 2006;118(1):e212-5.

80. In the matter of Central Admixture Pharmacy Services, Inc. Summary Suspension. Maryland State Board of Pharmacy. December 7, 2005. https://health.maryland.gov/pharmacy/docs/ FormalOrders/C/C.A.P.S\%2011-15-05.pdf. Accessed June 29, 2020.

81. Patel AS, Woolard D, McDonald LC, et al. Outbreak of Systemic Inflammatory Response Syndrome Linked to a Compounding Pharmacy - Virginia, 2005. In: 55th Annual Epidemic Intelligence Service Conference. Centers for Disease Control and Prevention; 2006: Poster 14.

82. Gershman MD, Kennedy DJ, Noble-Wang J, Kim C, Gullion J, Kacica M, et al. Multistate outbreak of Pseudomonas fluorescens bloodstream infection after exposure to contaminated heparinized saline flush prepared by a compounding pharmacy. Clin Infect Dis. 2008;47(11):1372-9.

83. Sunenshine RH, Tan ET, Terashita DM, Jensen BJ, Kacica MA, Sickbert-Bennett EE, et al. A multistate outbreak of Serratia marcescens bloodstream infection associated with contaminated intravenous magnesium sulfate from a compounding pharmacy. Clin Infect Dis. 2007;45(5):527-33.

84. Gupta N, Hocevar SN, Moulton-Meissner HA, Stevens KM, McIntyre MG, Jensen B, et al. Outbreak of Serratia marcescens bloodstream infections in patients receiving parenteral nutrition prepared by a compounding pharmacy. Clin Infect Dis. 2014;59(1):1-8.

85. Compounding: inspections, recalls, and other actions against $\mathrm{NuVision}$ Pharmacy; Dallas, TX. United States Food and Drug Administration. April 7, 2013. http://www.fda.gov/ downloads/AboutFDA/ CentersOffices/OfficeofGlobalRegulatoryOperationsandPolicy/ORA/ 
ORAElectronicReadingRoom/UCM348772.pdf. Accessed June 29, 2020.

86. Compounding: inspections, recalls, and other actions against Specialty Compounding, LLC; Cedar Park, TX. United States Food and Drug Administration. September 13, 2013. http:// www.fda.gov/downloads/AboutFDA/CentersOffices/ OfficeofGlobalRegulatoryOperationsandPolicy/ORA/ ORAElectronicReadingRoom/ UCM368579.pdf. Accessed June 29, 2020.

87. Lau B, Khazanie U, Rowe E, Fauman K. How a drug shortage contributed to a medication error leading to baclofen toxicity in an infant. J Pediatr Pharmacol Ther. 2016;21(6):527-9.

88. FDA announces voluntary recall of all unexpired human and animal compounded drug products produced by Reliable Drug Pharmacy, San Francisco. United States Food and Drug Administration. March 30, 2016. https://www.fda.gov/drugs/ drug-safety-and-availability/fda-announces-voluntary-recall-allunexpired-human-and-animal-compounded-drug-productsproduced. Accessed June 29, 2020.

89. Mody R, Rainbow J, Ferguson B, Wiberg C. Outbreak of Mycobacterium chelonae skin infections associated with human chorionic gonadotropin injections at weight loss clinics. Open Forum Infectious Diseases: In; 2018.

90. FDA warns compounders not to use glutathione from Letco Medical to compound sterile drugs. United States Food and Drug Administration. February 1, 2019. https://www.fda.gov/ drugs/drug-safety-and-availability/fda-warns-compounders-notuse-glutathione-letco-medical-compound-sterile-drugs. Accessed June 29, 2020.

91. McKeown N, Horowitz B, Garlich F, Young C, Robertson W. Deaths from intravenous colchicine resulting from a compounding pharmacy error - Oregon and Washington, 2007. MMWR Morb Mortal Wkly Rep. 2007;56(40):1050-2.

92. Boyce JM, Lee L, Topal J, Peaper DR, Balcezak T. Response to mold contamination of intravenous magnesium sulfate produced by a compounding pharmacy. JAMA Intern Med. 2014;174(4): 630.

93. Dodd DA, Burger J, Frangoul H, Dawling S. The risk of using compounded immunosuppressants in children. In: 5 th Congress of the International Pediatric Transplant Association; 2009: Abstract 358.

94. Al-Ahmadi M, Lazo-Langner A, Mangel J, Phm ADB, Liu K, Minuk L. Effect of unintentional cyclophosphamide underdosing on diffuse large B-cell lymphoma response to chemotherapy: a retrospective review. CMAJ Open. 2016;4(2):E236-9.

95. FDA Announces Pharmakon Pharmaceuticals Voluntary Recall of Morphine Sulfate $0.5 \mathrm{Mg} / \mathrm{ML}$ Preservative Free in $0.9 \%$ Sodium Chloride. United States Food and Drug Administration. 2016. https://www.fda.gov/drugs/drug-safety-and-availability/fdaannounces-pharmakon-pharmaceuticals-voluntary-recallmorphine-sulfate-05-mgml-preservative-free. Accessed June 6, 2020.

96. FDA Announces Glades Drugs' Nationwide Voluntary Recall of Compounded Multivitamins Containing High Amounts of Vitamin D3 (Cholecalciferol). United States Food and Drug Administration. 2015. https://wayback.archive-it.org/7993/ 20170112003911/http://www.fda.gov/Drugs/DrugSafety/ ucm474552.htm. Accessed June 6, 2020.

97. Coyne PJ, Hansen LA, Watson AC. Compounded drugs: are customized prescription drugs a salvation, snake oil, or both? Am J Nurs. 2003;103(5):78-85.

98. O’Brien D, Cohen I, Kennedy DJ. Compounding pharmacies: a viable option, or merely a liability? PM\&R. 2013;5(11):974-81.

99. Blank C. Time for compounding certification? Drug Topics August 18, 2015. https://www.drugtopics.com/view/it-timenational-compounding-certification. Accessed June 27, 2020.
100. Guidance - prescribing of liothyronine. National Health Service England - Specialist Pharmacy Service. July 19, 2019. https:// www.sps.nhs.uk/articles/updated-rmoc-guidance-prescribing-ofliothyronine/. Accessed June 29, 2020.

101. Randell MD. Risk and liabilities of prescribing compounded medications. Postgrad Med. 2014;126(4):4.

102. Thomas K. U.S. hospitals wrestle with shortages of drug supplies made in Puerto Rico. The New York Times. October 23, 2017. https://www.nytimes.com/2017/10/23/health/puerto-ricohurricane-maria-drug-shortage.html. .

103. Statement by FDA Commissioner Scott Gottlieb, M.D.: update on recovery efforts in Puerto Rico, and continued efforts to mitigate IV saline and amino acid drug shortages. United States Food and Drug Administration. January 4, 2018. https://www.fda.gov/ news-events/press-announcements/statement-fda-commissionerscott-gottlieb-md-update-recovery-efforts-puerto-rico-andcontinued. Accessed June 27, 2020.

104. Digon S. COVID-19 lockdown: reports indicate shortage in antidepressants. International Business Times June 2, 2020. https:// www.ibtimes.com/covid-19-lockdown-reports-indicate-shortageantidepressants-2986197. Accessed June 27, 2020.

105. Silverman E. Hospitals see shortages of a cheap steroid that one study says helps COVID-19 patients. STAT News June 25, 2020. https://www.statnews.com/pharmalot/2020/06/25/covid19coronavirus-dexamethasone-shortages/. Accessed June 27, 2020.

106. Romano MJ, Dinh A. A 1000-fold overdose of clonidine caused by a compounding error in a 5-year-old child with attention-deficit/hyperactivity disorder. Pediatrics. 2001;108(2):471-2.

107. Suchard JR, Graeme KA. Pediatric clonidine poisoning as a result of pharmacy compounding error. Pediatr Emerg Care. 2002;18(4): 295-6.

108. Farooqi MF, Seifert SA, Kunkel SJ, Johnson MI, Benson BE. Toxicity from a clonidine suspension. J Med Toxicol. 2009;5(3): 130-3.

109. Biary R, Makvana S, Hussain AZ, et al. Prolonged hypertension from a 1,000 fold clonidine compounding error. In: North American Congress of Clinical Toxicology Annual Meeting; 2013.

110. Barbuto AF, Burns MM. Clonidine compounding error: bradycardia and sedation in a pediatric patient. J Emerg Med. 2020;59(1): 53-5.

111. Rao R, O’Neill M, Sperling J, et al. Akathisia in two patients following newly compounded 4-aminopyridine. In: North American Congress of Clinical Toxicology Annual Meeting; 2010.

112. Schwam E. Severe accidental overdose of 4-aminopyridine due to a compounding pharmacy error. J Emerg Med. 2011;41(1):51-4.

113. Thompson JF. Unintentional 4-aminopyridine overdose in a multiple sclerosis patient: case presentation with a focus on intervention. J Pharm Technol. 2013;29(6):255-9.

114. Watts D, Gresham C, Pitera A, Wax P, Ruha AM. Thyroid storm from a liothyronine compounding error. In: North American Congress of Clinical Toxicology Annual Meeting; 2009.

115. De La Calzada-Jeanlouie MF, Greller HA, Su MK, Chan GM. A case of thyrotoxicosis due to a compounding error. In: North American Congress of Clinical Toxicology Annual Meeting; 2011.

116. Shah KK, Mbughuni MM, Burgstaler EA, Block DR, Winters JL. Iatrogenic thyrotoxicosis and the role of therapeutic plasma exchange. J Clin Apheresis. 2017;32(6):579-83.

117. Hadzija BW, Shrewsbury RP. Atropine overdosage with a suppository formulation containing atropine sulfate. Int J Pharm Compd. 1997;1(4):271-3.

118. Bachman G, Hon S, Lopez G. Beware of what is in the mixture: calculation error in compounded GI cocktail. In: North American Congress of Clinical Toxicology Annual Meeting; 2019. 
119. Wheeler J, Francis P, Kim J. Atenolol compounding and atrioventricular block: a case report. In: Journal of Investigative Medicine Western Regional Meeting; 2012.

120. Wang GS, Tham E, Maes J, Buchanan JA. Flecainide toxicity in a pediatric patient due to differences in pharmacy compounding. Int J Cardiol. 2012;161(3):178-9.

121. Barillas JE, Eichner D, Van Wagoner R, Speiser PW. Iatrogenic cushing syndrome in a child with congenital adrenal hyperplasia: erroneous compounding of hydrocortisone. J Clin Endocrinol Metab. 2018;103(1):7-11.

122. Butt N, John J, Ettinger A, et al. Pyrimethamine-induced seizure caused by compounding error. In: North American Congress of Clinical Toxicology Annual Meeting; 2014.

123. Lowry JA, Vandover JC, DeGreeff J, Scalzo AJ. Unusual presentation of iatrogenic phenytoin toxicity in a newborn. J Med Toxicol. 2005;1(1):26-9.

124. FDA alerts patients and health care providers not to use budesonide solution from The Compounding Shop. United States Food and Drug Administration. September 27, 2013. http://web.archive.org/web/20131007102425/http://www.fda. gov/Drugs/DrugSafety/ucm370103.htm. Accessed June 6, 2020.

125. FDA alerts health care professionals not to use sterile drugs from Downing Labs (Aka NuVision Pharmacy). United States Food and Drug Administration. July 18, 2014. https://wayback. archive-it.org/7993/20170112003920/http://www.fda.gov/Drugs/ DrugSafety/ucm405940.htm. Accessed June 6, 2020.

126. FDA announces Medistat RX's nationwide voluntary recall of sterile drug products. United States Food and Drug Administration. September 9, 2015. https://wayback.archive-it. org/7993/20170112003913/http://www.fda.gov/Drugs/ DrugSafety/ucm461810.htm. Accessed June 6, 2020.

127. FDA alerts health care professionals not to use sterile drug products from Qualgen. United States Food and Drug Administration. October 10, 2015. https://wayback.archive-it.org/7993/ 20170112003912/http://www.fda.gov/Drugs/DrugSafety/ ucm466522.htm. Accessed June 6, 2020.

128. FDA alerts health care professionals and patients not to use sterile drug products from Medaus Pharmacy, Birmingham, Alabama. United States Food and Drug Administration. April 1, 2016. https://www.fda.gov/drugs/drug-safety-and-availability/fda-alertfda-alerts-health-care-professionals-and-patients-not-use-steriledrug-products-medaus. Accessed June 6, 2020.

129. FDA announces Pharmakon Pharmaceuticals' nationwide voluntary recall of purportedly sterile drug products. United States Food and Drug Administration. May 6, 2016. https://www.fda.gov/ drugs/drug-safety-and-availability/fda-announces-pharmakonpharmaceuticals-nationwide-voluntary-recall-purportedly-steriledrug. Accessed June 6, 2020.
130. FDA alerts health care professionals and patients not to use sterile drug products from Vital Rx, Dba Atlantic Pharmacy and Compounding. United States Food and Drug Administration. August 10, 2017. https://www.fda.gov/drugs/drug-safety-andavailability/fda-alerts-health-care-professionals-and-patients-notuse-sterile-drug-products-vital-rx-dba. Accessed June 6, 2020.

131. FDA alerts health care professionals to voluntary nationwide recall of all sterile products from Coastal Meds. United States Food and Drug Administration. April 13, 2018. https://www.fda.gov/drugs/ drug-safety-and-availability/fda-alerts-health-care-professionalsvoluntary-nationwide-recall-all-sterile-products-coastal-meds. Accessed June 6, 2020.

132. FDA announces Ranier's Rx Laboratory's voluntary recall of all sterile compounded drugs. United States Food and Drug Administration; July 31, 2018. https://www.fda.gov/drugs/drugsafety-and-availability/fda-announces-raniers-rx-laboratorysvoluntary-recall-all-sterile-compounded-drug. Accessed June 6, 2020.

133. FDA alerts health care professionals and patients not to use sterile drug products from Pharm D Solutions. U.S. Food \& Drug Administration. November 19, 2018. https:/www.fda.gov/drugs/ drug-safety-and-availability/fda-alerts-health-care-professionalsand-patients-not-use-sterile-drug-products-pharm-d-solutions. Accessed June 29, 2020.

134. FDA alerts health care professionals and patients not to use drug products intended to be sterile from Promise Pharmacy. United States Food and Drug Administration. December 7, 2018. https://www.fda.gov/drugs/drug-safety-and-availability/fdaalerts-health-care-professionals-and-patients-not-use-drugproducts-intended-be-sterile-promise. Accessed June 6, 2020.

135. FDA alerts patients and healthcare professionals to Infusion Options' voluntary recall due to quality issues. United States Food and Drug Administration. June 21, 2019. https://www.fda. gov/drugs/fda-alerts-patients-and-healthcare-professionalsinfusion-options-voluntary-recall-due-quality. Accessed June 6, 2020.

136. FDA announces Pacifico National Inc.'s, Dba AmEx Pharmacy, voluntary recall of all sterile compounded drugs. United States Food and Drug Administration. September 9, 2019. https:// www.fda.gov/drugs/drug-safety-and-availability/fda-announcespacifico-national-incs-dba-amex-pharmacy-voluntary-recall-allsterile-compounded-drugs. Accessed June 6, 2020.

Publisher's Note Springer Nature remains neutral with regard to jurisdictional claims in published maps and institutional affiliations. 